\title{
Spectrographic Determination of Minor Elements in Portland Cement ${ }^{1}$
}

\author{
By Armin W. Helz* and Bourdon F. Scribner
}

\begin{abstract}
A rapid spectrographic procedure for the determination of the minor metallic elements in portland cement is described. The method shows promise of easy extension to cement raw materials and many ceramic materials, provided reliable standard samples of these materials are available.

In the application of the method to portland cement, seven minor elements were determined. The precision in terms of probable error of a single determination is within 3 percent of the oxide concentration for aluminum, iron, magnesium, manganese, and titanium; 5 percent of the $\mathrm{Na}_{2} \mathrm{O}$ concentration; and 8 percent of the $\mathrm{K}_{2} \mathrm{O}$ concentration. Other minor elements, such as lithium, strontium, chromium, zirconium, and vanadium, may readily be included.

The spectrographic analyses of 21 portland cements are compared with chemical results for an estimate of the accuracy. Salient features of the procedure are (1) employing pellets consisting of the cement powder, with graphite as a binder, cobalt oxide as an internal standard, and potassium nitrate as a buffer, (2) applying the pellet as an electrode for excitation by an overdamped condenser discharge, and (3) photographing the spectrum with a step sector and a diffusing screen for obtaining uniformity of illumination.
\end{abstract}

\section{Introduction}

Portland cement is composed of several complex compounds of lime, alumina, silica, and iron oxide. Its approximate oxide composition is given in table 1. The usual chemical procedures for the analysis of cement are difficult and time-consuming. Unless special care is exercised in chemical separations, errors arise owing to interferences, thus $\mathrm{TiO}_{2}$ and $\mathrm{P}_{2} \mathrm{O}_{5}$ may be included with $\mathrm{Al}_{2} \mathrm{O}_{3}$; $\mathrm{Mn}_{2} \mathrm{O}_{3}$ with $\mathrm{MgO}$; and if minor alkali elements are present, $\mathrm{Li}_{2} \mathrm{O}$ with $\mathrm{Na}_{2} \mathrm{O}$; and $\mathrm{Cs}_{2} \mathrm{O}$ and $\mathrm{Rb}_{2} \mathrm{O}$ with $\mathrm{K}_{2} \mathrm{O}$. The spectrographic method offers marked advantages of speed, ease of execution, and relative freedom from personal error.

\footnotetext{
1 Presented at the meeting of the American Ceramic Society on April 30, 1946.

*Research Associate at the National Bureau of Standards, representing the Portland Cement Association.
}

TABLE 1.-Composition of portland cement

[Range and average of 41 commercial cements]

\begin{tabular}{|c|c|c|}
\hline Constituent & Range & Average \\
\hline $\mathrm{CaO} \ldots$ & $\begin{array}{c}\text { Percent } \\
59.6 \text { to } 67.0\end{array}$ & $\begin{array}{l}\text { Percent } \\
63.6\end{array}$ \\
\hline $\mathrm{SiO}_{2} \ldots \ldots$ & 20.0 to 27.5 & 22.3 \\
\hline $\mathrm{Al}_{2} \mathrm{O}_{3} \ldots \ldots$ & 2.0 to 6.3 & 4.7 \\
\hline $\mathrm{Fe}_{2} \mathrm{O}_{3} \ldots \ldots$ & 1.9 to 5.5 & 3.4 \\
\hline $\mathrm{MgO}_{\ldots} \ldots \ldots$ & 0.7 to 4.4 & 2.1 \\
\hline $\mathrm{SO}_{3} \ldots \ldots$ & 1.3 to 2.3 & 1.8 \\
\hline $\mathrm{Na}_{2} \mathrm{O} \ldots \ldots$ & 0.03 to 1.2 & 0.25 \\
\hline $\mathrm{K}_{2} \mathrm{O}$ & .04 to 1.4 & .45 \\
\hline $\mathrm{P}_{2} \mathrm{O}_{5}$ & .03 to .46 & .14 \\
\hline $\mathrm{Mn}_{2} \mathrm{O}_{3} \ldots$ & .03 to .50 & .18 \\
\hline $\mathrm{TiO}_{2}$ & .10 to .30 & .22 \\
\hline Ignition loss & .60 to 2.2 & 1.0 \\
\hline Insoluble residue & 1. 02 to .40 & 0.14 \\
\hline
\end{tabular}

The intial application of the spectrograph to the analysis of portland cement by the Bureau's spectrochemical laboratory was made on the de- 
termination of the alkali elements [1]. ${ }^{2}$ The fullest advantage of a spectrographic method is realized when a number of elements are determined simultaneously. Consequently, an investigation was undertaken to extend the determinations to include aluminum, iron, magnesium, manganese, and titanium. At the same time the possibility of applying a modified technic to improve the alkali determinations was considered.

In the method previously reported for the alkalis, a fixed amount of the sample mixture was placed in the crater of a graphite electrode that formed the lower positive element of direct-current arc. This method has the advantages of employing the relatively inexpensive direct-current type of excitation and providing for the detection of very low concentrations. The disadvantages of the method are (1) the requirement of red-sensitive plates that tend to be nonuniform, (2) the difficulty of handling small samples in powder form, and (3) the requirement of additional procedures for lithium and for high potassium concentrations. The procedure to be described has none of these disadvantages and permits the determination of aluminum, iron, magnesium, potassium, sodium, manganese, and titanium. In addition, lithium, strontium, chromium, zirconium, and vanadium were considered, but they were not found in any of the cements analyzed in sufficient quantities to warrant their detailed study. Lines of these elements suitable for observing concentrations down to about 0.1 percent are found in the same spectral region used for the other elements. Calcium, silicon, sulfur, and phosphorus are not determined by this method. The first two elements, because of their high concentration, cannot be determined with sufficient precision to rival chemical methods. The latter two elements have poor spectral sensitivity, and special procedures would be required for their determination. The method shows promise of easy extension to the analysis of cement raw materials and many ceramic materials, if reliable standard samples of these materials are available.

\section{Development of the Method}

\section{Spectrographic Studies}

In the paper on the determination of the alkalies in portland cement [1] the K 7698.98 and $\mathrm{Na}$

\footnotetext{
${ }^{2}$ Figures in brackets indicate the literature references at the end of this paper.
}

8194.81 A lines were used in preference to $\mathrm{K}$ 4044.14 A and $\mathrm{Na} 3302.32 \mathrm{~A}$ because of the higher intensity and greater freedom from background. The shorter wavelength potassium and sodium lines are much more useful because of their proximity in wavelength to lines of other minor elements. The procedure described in this paper successfully makes use of the K 4044.14 and $\mathrm{Na}$ 3302.32 A lines through the choice of excitation, and the form and composition of the electrode. The potassium line tends to be broad and diffuse. This, however, does not seriously impair its usefulness for quantitative work.

There was no difficulty in finding suitable iron, magnesium, and titanium arc lines. Their selection was based on consideration of intensity, proximity to other lines being measured, and freedom from interfering lines. Limitations of intensity and background narrowed the choice of magnesium lines. The $\mathrm{Mg} 3332.13$ A line was successfully used, though it tends to be weak and diffuse. Attempts were made to use an aluminum line falling within the region 2800 to 4200 A photographed for the other elements. Aluminum lines in this region were either too intense or failed to show a favorable intensity-concentration response. For this reason the $\mathrm{Al} 2660.39 \mathrm{~A}$ line was selected. A coincident line, Fe 2660.40 A, did not interfere with the aluminum line at the concentrations of iron encountered in cements. The weaker line, Al 2652.49 A, is suggested as an alternate for the determination of aluminum.

The spectrum was photographed with a Baird grating spectrograph having a linear disperson of approximately $5.5 \mathrm{~A}$ per millimeter. An intensity pattern is obtained with a five-step rotating sector and a thin silica lens, the combination being located at the secondary focus of the spectrograph. The lens serves to focus an image of the are on the grating of the spectrograph. This arrangement is not sufficient for obtaining uniform illumination as the arc is very large and the distribution of the intensities of the lines of the several elements varies at different points in the arc. This is particularly true of the alkali lines as compared with those of the internal standard and the other elements sought. This difficulty is minimized by placing a diffusing screen at the position where the arc would normally be and moving the are to a position $8 \mathrm{~cm}$ behind the screen. 
The arc stand has been described by Scribner and Corliss [2]. The adapter (fig. 1) used to hold $1 / 2$-in.-diameter pellet electrodes in this stand will also serve with any other electrode holder that will clamp rods $1 / 4 \mathrm{in}$. in diameter in accurate alinement. The clamping action of the stand on the split rod of the adapter securely clamps the sides of the pellet. The pellet extends well above the rim of the adapter so that the arc strikes only the top face of the pellet. With proper clamping, the

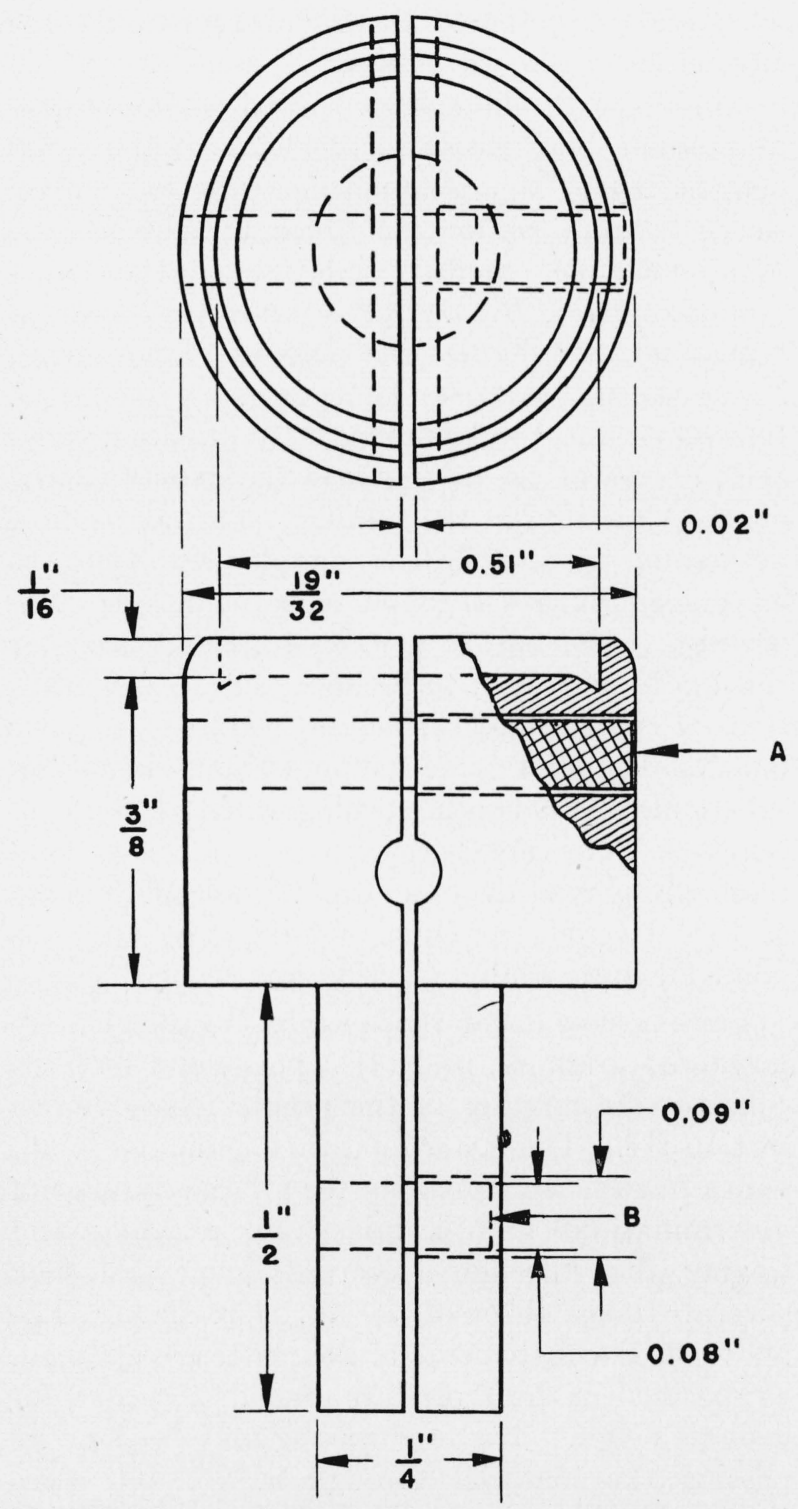

Figure 1.-Pellet holder, front and top views.

It is made by turning two pieces of brass clamped together with a metal spacer 0.02 in. thick. Two steel-pin guides $(A, B)$ are soldered to the left side and extend into oversized holes in the right side. bottom of the pellet and the adapter remain perfectly clean and free from burning.

The diffusion screen is similar to that discussed by Hansen [3] and consists of a vitreous silica plate, $45 \mathrm{~mm}$ in diameter, ground, and etched for maximum transmission, with good diffusion. It is made by grinding a clear silica plate on one side with grade $F$ silicon carbide and then etching in dilute hydrofluoric acid for about half an hour. The etching is discontinued when inspection with magnifying lens shows that the irregular scratches of the grinding are smoothed out into hemispherical pits. Details of photography, microphotometry, and calculations follow standard procedures, and for which adequate references are available $[4,5]$.

\section{Method of Excitation}

Three means of excitation were investigated (1) direct-current arc, (2) alternating-current arc, and (3) overdamped-condenser discharge. The latter appeared more promising for a simultaneous determination of all minor elements than the other types of excitation. Tests indicated that insufficient reproducibility was obtained for the alkalis with the d-c or a-c ares, but such ares did show possibilities of giving satisfactory results for other minor elements.

The overdamped-condenser discharge was obtained with a "multisource unit" $[6,7]$. This instrument supplies a large number of discharges intermediate between the electric arc and electric spark. The arc-like discharge was chosen because of sensitivity and interference considerations, and has the current characteristic shown in figure 2 . The circuit constants given in the procedure below are optimum for reliable operation of the power unit under high-energy and high-damping requirements. The large gap is essential for stable operation and the negative polarity of the samplebearing electrode was chosen because of enhanced spectral intensity.

\section{Electrode Form, Composition, and Preparation}

Numerous tests showed that improved reproducibility could be obtained with the pellet method of placing the sample in the arc, furthermore, the spectral background was considerably reduced. The pellets are disk-shaped $1 / 2$ in. $(13 \mathrm{~mm})$ in diameter and $1 / 8 \mathrm{in} .(3 \mathrm{~mm})$ thick. 


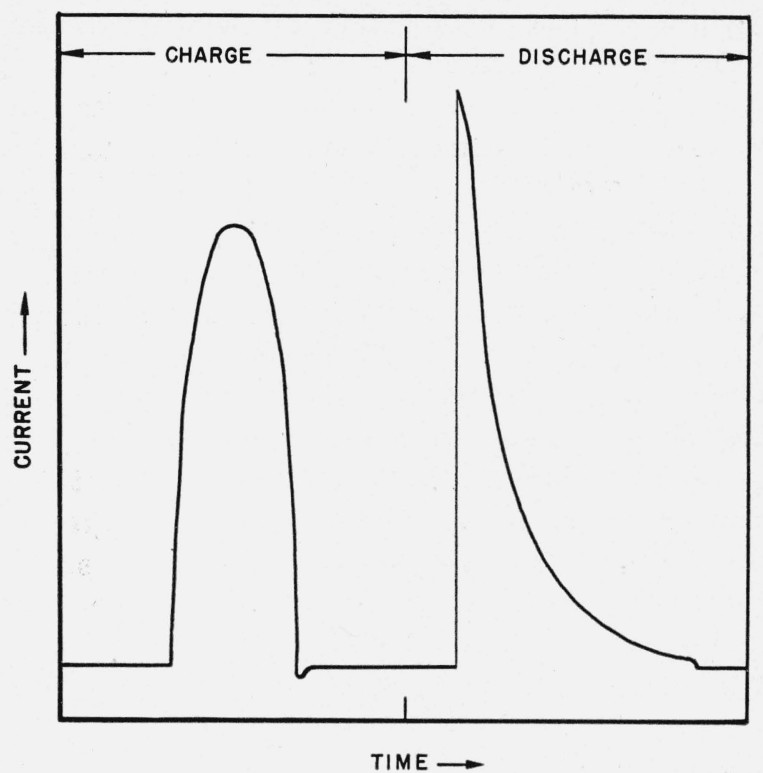

FIGURE 2.--Sketch of oscillogram of overdamped-condenser discharge, showing the change of current with time for charge and discharge of the condenser.

Second-grade spectroscopic rods $1 / 8$ in. in diameter cut into electrodes $3 / 4$ in. (19 mm) in length and rounded at one end served as the upper, positive, electrode.

Graphite proved to be an ideal admixture with the cement for obtaining a pellet which, upon burning, was slow to form a crust. With this type of pellet a constant ratio of intensities of lines of the various elements is maintained for a fairly long burning time. The concentration of cement was made as high as possible in order to obtain suitable intensities of the desired lines (particularly for the alkalis). The upper limit was found to be about 60 percent cement, which, if exceeded, produced erratic burning and crust formation.

Cobalt oxide is added for the internal standard. Cobalt has a sufficient number of lines to provide suitable reference lines in any part of the spectrum, and has evaporation and excitation characteristics that are a fairly good average of the properties of the elements sought. The purest compound of cobalt available was $\mathrm{Co}\left(\mathrm{NO}_{3}\right)_{2} \cdot 6 \mathrm{H}_{2} \mathrm{O}$, from which the oxide was prepared. ${ }^{3}$

An important problem was the effect of varying

3 Cobalt oxide was prepared by carefully heating the nitrate in a Pyrex beaker to remove water and oxides of nitrogen. The product was crushed and passed through a No. 48 sieve and then transferred to a platinum dish and heated to about $900^{\circ} \mathrm{C}$ for several hours. Finally, the oxide was passed through a No. 200 sieve. potassium content on the intensity ratio of sodium to cobalt. The spectra of other minor elements showed little alteration with respect to cobalt lines. The choice of another internal standard, strontium, for example, would prove better for sodium but poorer for the other minor elements. A single internal standard could not be ideal for all the elements in question because of difference in properties of the elements to be determined. The method and reason for reducing the potassium interference in preference to adding a second internal standard follows. It was observed that the interference due to potassium tends toward a maximum with increasing potassium concentration-there being little further change above 1.0 percent $\mathrm{K}_{2} \mathrm{O}$. It was found desirable to increase the potassium content in order to increase the potassium line intensity relative to the background. Thus, by adding a known amount of potassium as a buffer, the amount of potassium in the sample could be determined by difference. Increasing the total amount of potassium, however, decreases the accuracy of the determination of the potassium in the sample. The addition of potassium nitrate to the sample equivalent to 0.7 percent $\mathrm{K}_{2} \mathrm{O}$ was found to be a suitable compromise. The nature of the compound used for this addition proved to be important. The addition of potassium carbonate resulted in poor burning behavior whereas potassium nitrate resulted in very smooth burning with all types of cements. The arc under these conditions continuously played over the central half of the area of the electrode without remaining at any one point for more than a fraction of a second.

The ingredients of a pellet are (1) cement, (2) powdered graphite, and (3) a potassium nitratecobalt oxide mixture in the proportions given in section III. The latter mixture is prepared in advance in sufficient quantity for a large number of determinations and is mixed by grinding and sieving, first through a No. 325 sieve and then several times through a No. 200 sieve. The above three constituents of the pellet are weighed, as specified in the procedure, mixed, and used for a single pellet. The final mixing may be done by passing the material through a No. 100 sieve three or more times. However, the following procedure for mixing is faster, with less chance of introducing errors. A number of vials are pre- 
pared, each one to hold a sample mixture. ${ }^{4} \quad$ A vial containing the ingredients of a pellet is placed in a plastic holder, shown in figure 3 , and clamped to an electric-motor shaker for mixing. The clamp is designed to press the cover ${ }^{5}$ against the vial and to hold the entire assembly in place. A dentaltype amalgamator shakes the vial in a figure-8 motion at high speed. Twenty seconds of shaking
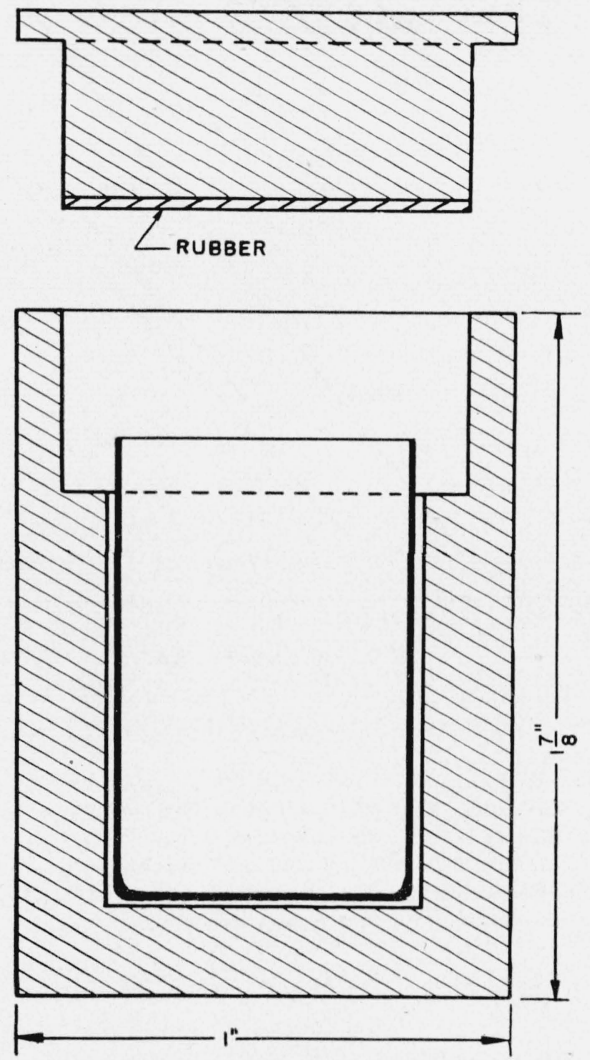

FiguRe 3.-Plastic holder and cover (Lucite) for mixing, showing a glass vial in place.

The rubber lining of the cover is cut from a dental rubber dam $0.014 \mathrm{in}$. thick.

is sufficient for complete mixing. A number of sample mixtures are prepared simultaneously. When making a pellet the complete contents of a vial is poured into the mold. Sufficient pressure is applied in the press to give a well-formed, compact pellet capable of easy handling.

${ }_{4}^{4}$ The vials are prepared by cutting off thin glass vials $5,8 \mathrm{in}$. (16 mm) in diameter, and grinding, and polishing the open ends to a total length of $136 \mathrm{in}$. (35 mm)

${ }^{5} \mathrm{~A}$ thin rubber sheet cemented to the cover of the holder and pressed against the ground and polished ends of the vials efficiently retains the material during mixing.

\section{Spectrographic Analysis of Portland Cement} $734742-47-4$

\section{Procedure}

The following three materials are weighed into a glass vial for mixing: (1) Spectrographic graphite powder (note 1, table 2) $0.440 \mathrm{~g}$; (2) potassium nitrate-cobalt oxide mixture, $0.0575 \mathrm{~g}$; (3) portland-cement sample, $0.500 \mathrm{~g}$. Mixture 2 is prepared with $5.000 \mathrm{~g}$ of cobalt oxide and $0.750 \mathrm{~g}$ of potassium nitrate, as already described. If the cement has been stored for a considerable time or exposed to air, it should be ignited at $900^{\circ} \mathrm{C}$ and passed through a No. 100 sieve. Pellets are formed in a mold $1 / 2 \mathrm{in}$. in diameter at a total load of about 8,500 pounds. The value of the pressure is not critical, except that it should be kept constant. Any burrs on the pellet are scraped off and the pellet brushed clean, all handling being done with forceps. Details for making the spectrogram are outlined in table 2.

TABLE 2.-Operating conditions for analysis of porlland cernent

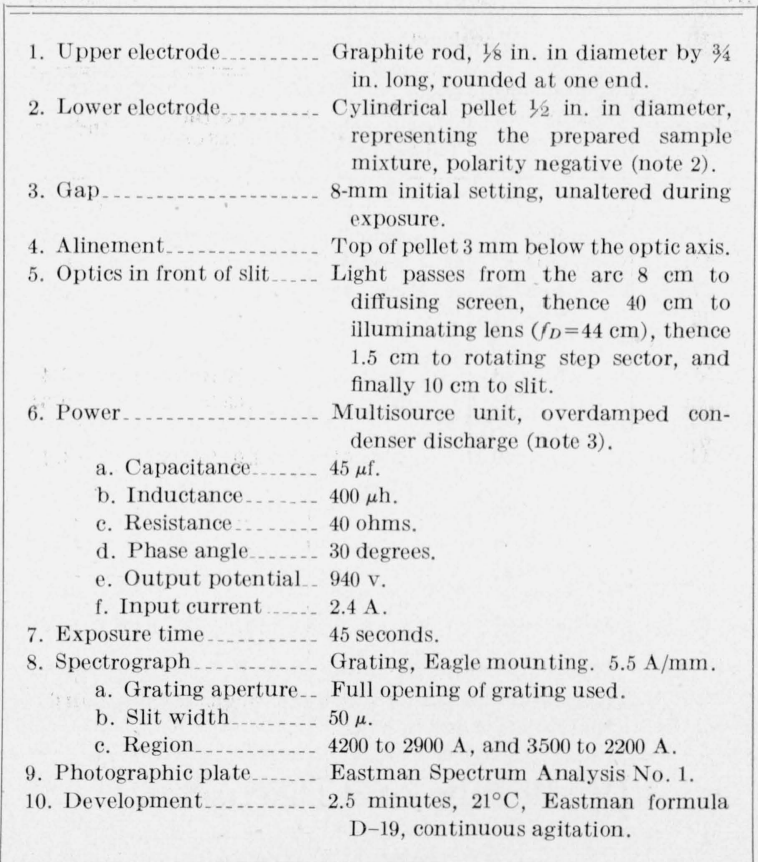

Note 1.-A pure form of graphite powder suitable for forming the pellets was obtained from the National Carbon Co.

Note 2.- One side of the pellet may be used for the aluminum determination and the other side for the other elements when the apparatus will not permit covering the entire region $(4,100$ to $2,600 \mathrm{~A})$ with a single exposure.

Note 3.-Before running samples for analysis, the source unit must be warmed-up by running several blanks.

Reduction of measurements follows standard procedures. Intensities of the lines of the elements sought relative to the intensities of neighboring 
cobalt lines are derived from plate characteristic curves (transmittancy vs. log relative intensity) established for each of the first three groups of lines indicated in table 3 . The log intensity ratios are converted to concentrations of the elements by means of analytical curves. The latter are determined by applying the same spectrographic procedure to portland cements of known composition. The majority of photometric measurements are made in the second and third steps of the intensity pattern. The $\mathrm{Li}, \mathrm{Cr}, \mathrm{Sr}, \mathrm{V}$, and $\mathrm{Zr}$ lines listed in table 3 are for qualitative observation. These elements were not found in appreciable amounts in any of the 41 cements studied. Therefore, the lines were not tested for quantitative work but are of an intensity suitable for detecting oxide concentrations in the neighborhood of 0.05 percent. A weak cobalt line tends to interfere with the lithium line, but lithium can be detected in amounts as low as 0.1 percent of $\mathrm{Li}_{2} \mathrm{O}$.

TABLE 3.-Lines employed in the analysis of portland cement

[Wavelengths in angstroms]

\begin{tabular}{|c|c|c|c|c|}
\hline Element & $\begin{array}{c}\text { Analytical } \\
\text { line }\end{array}$ & $\begin{array}{c}\text { Internal } \\
\text { standard } \\
\text { (cobalt lines) }\end{array}$ & $\begin{array}{l}\text { Concentration } \\
\text { range (as oxide) }\end{array}$ & Index a \\
\hline & & & Percent & Percent \\
\hline K & 4044.14 & 4020.90 & 0.04 to 1.4 & 1.3 \\
\hline $\mathrm{Mn}$ & 4041.37 & 4020.90 & .03 to 0.50 & 0.15 \\
\hline $\mathrm{Fe}$ & 4005.25 & 4020.90 & 1.9 to 5.5 & 2.6 \\
\hline $\mathrm{Ti}$ & 3998.64 & 4020.90 & 0.10 to 0.30 & 0.18 \\
\hline $\mathrm{Mg}$ & 3332.15 & 3322.20 & .70 to 4.4 & 3.4 \\
\hline $\mathrm{Na}$ & 3302.32 & 3322.20 & .03 to 1.2 & 0.34 \\
\hline Al & 2660.39 & 2648.64 & 2.0 to 6.3 & 4. 4 \\
\hline $\mathbf{L i}$ & 3232.61 & $\ldots$ & & (........... \\
\hline $\mathrm{Cr}$ & 3578.69 & - & - & (.......... \\
\hline $\mathrm{Sr}$ & 3464.46 & ............ & - & -........ \\
\hline V & 3183.41 & - & - & (......... \\
\hline $\mathrm{Zr}$ & 3391.97 & - & - & - n. \\
\hline
\end{tabular}

a The index is the concentration for which the intensities of the analytical line and the internal standard line are equal.

\section{Results and Discussion}

\section{Analytical Curves}

Figure 4 illustrates the analytical curves as determined from the reference series of 20 cements discussed in section IV, 3. The curves are not directly applicable in another laboratory because they are a function of the particular spectrographic installation. All the analytical curves are straight lines, except that for aluminum. An auxiliary scale, shown for the potassium curve, automati-

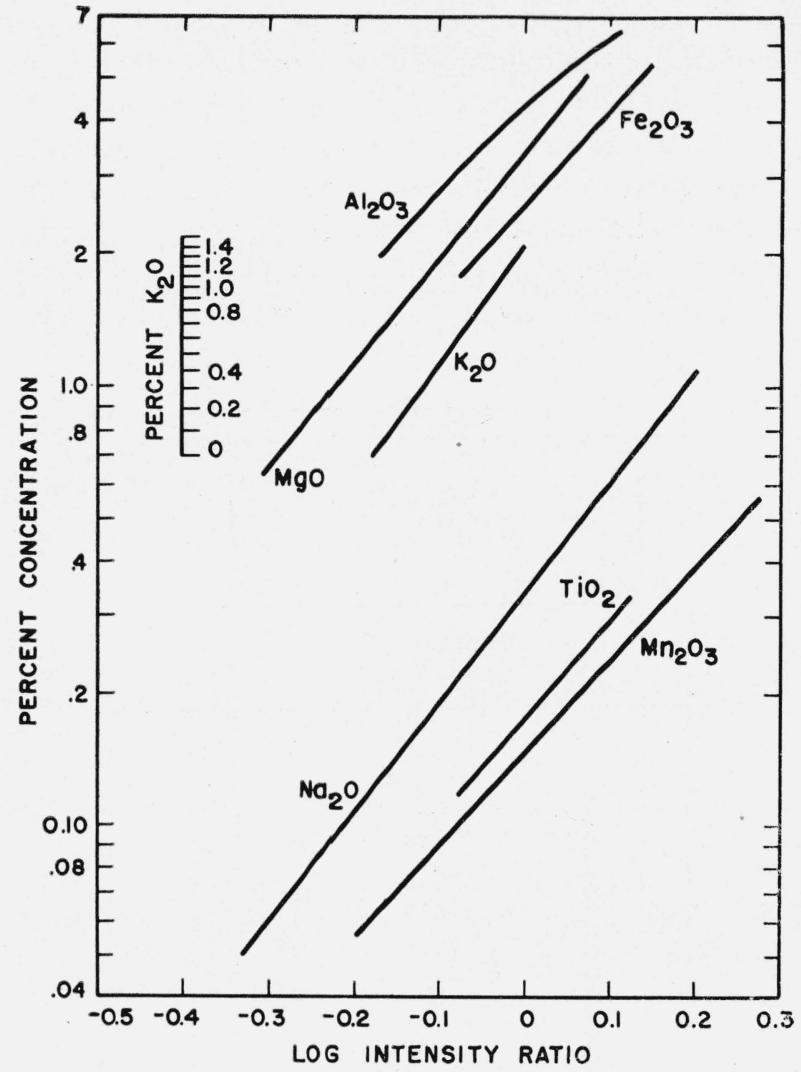

FIGURE 4.-Analytical curves for the analysis of portland cement.

The log intensity ratio and the percentage concentration are plotted for the following line pairs: $\mathrm{K}$ 4044.14/Co 4020.90; $\mathrm{Mn}$ 4041.37/Co 4020.90; $\mathrm{Fe}$ 4005.25/Co 4020.90; Ti 3998.64/Co 4020.90; Mg 3332.15/Co 3322.20; Na 3302.32/ Co $3322.20 ; \mathrm{Al} 2660.39 / \mathrm{Co} 2648.64$. The auxiliary concentration scale for potassium oxide corrects for potassium added to the sample. The analytical curves are shown for illustrative purposes only.

cally deducts the 0.7 percent of $\mathrm{K}_{2} \mathrm{O}$ added to the sample.

The analytical curves have been found to be quite stable in general, but an unexplained shift has been observed for the potassium curve. This shift has occurred after an interruption in the work for about a month. This indicates the advisability of periodic check-ups on the potassium determination with standard samples.

\section{Precision of Determinations}

Estimates of precision were based on 6 determinations of the minor elements in 8 portland cements, or 48 determinations in all. The precision is an indication of the degree of reproducibility but does not indicate constant errors due to such factors as chemical combinations of the minor elements, varying composition of the major 
elements, interfering elements, self-reversal, etc. Good precision, however, is a necessary condition for accuracy. In the second column of table 4, estimates of precision in terms of percentage concentration of the component are given.

TABLE 4.-Precision and accuracy of determinations of constituents in portland cement

\begin{tabular}{|c|c|c|}
\hline Component & $\begin{array}{l}\text { Precision }{ }^{1} \\
\text { (probable } \\
\text { error ( } \% \text { of of } \\
\text { a single de- } \\
\text { termination) }\end{array}$ & $\begin{array}{l}\text { A ceuracy }{ }^{2} \\
\text { (average con- } \\
\text { centration dif- } \\
\text { ference (\%) } \\
\text { of sample) }\end{array}$ \\
\hline $\mathrm{Al}_{2} \mathrm{O}_{3 \ldots}$ & 3 & 0.25 \\
\hline $\mathrm{Fe}_{2} \mathrm{O}_{3} \ldots$ & 2 & .12 \\
\hline $\mathrm{MgO}$ & 3 & .14 \\
\hline $\mathrm{Na}_{2} \mathrm{O}$ & 5 & .02 \\
\hline $\mathrm{K}_{2} \mathrm{O}$ & 8 & .06 \\
\hline $\mathrm{Mn}_{2} \mathrm{O}_{3}$ & 3 & .01 \\
\hline $\mathrm{TiO}_{2} \ldots$ & 2 & .01 \\
\hline
\end{tabular}

1 Based on reproducibility.

2 Based on differences between spectrographic and chemical determinations.

The probable error of a single determination is within 3 percent of the oxide concentration for aluminum, iron, magnesium, manganese, and titanium, 5 percent of the $\mathrm{Na}_{2} \mathrm{O}$ concentration, and 8 percent of the $\mathrm{K}_{2} \mathrm{O}$ concentration. The larger values for the alkalis may be due to different characteristics of volatility and excitation for the alkalis and the internal standard. Ease of contamination and the necessity of adding potassium nitrate to the sample, with the subsequent problem of mixing, may also be contributing factors to decreased precision for the alkalis.

\section{Accuracy of Determinations}

A measure of accuracy is obtained by comparing the chemical and spectrographic results of a large number of cements. Thus, possible effects of varying composition and of interfering elements are included. Two groups of cement samples that had been carefully analyzed were available. One group of 20 cements was used for determining the analytical curves, the second group of 21 cements was analyzed as unknown. The use of analyzed cements for standards -is considered a more trustworthy procedure than the use of synthesized standards. In order to avoid the effects of differences in chemical combinations, the synthesized standard mixtures would have to be

TABLE 5.-Comparison of spectrographic and chemical results for 21 portland cements-weight percent

\begin{tabular}{|c|c|c|c|c|c|c|c|c|c|c|c|c|c|c|c|c|c|c|c|c|c|}
\hline \multirow[b]{2}{*}{ No. } & \multicolumn{3}{|c|}{$\mathrm{Al}_{2} \mathrm{O}_{3^{\mathrm{a}}}$} & \multicolumn{3}{|c|}{$\mathrm{Fe}_{2} \mathrm{O}_{3} \mathrm{a}$} & \multicolumn{3}{|c|}{$\mathrm{MgO}^{9}$} & \multicolumn{3}{|c|}{$\mathrm{Na}_{2} \mathrm{O}$} & \multicolumn{3}{|c|}{$\mathrm{K}_{2} \mathrm{O}$} & \multicolumn{3}{|c|}{$\mathrm{Mn}_{2} \mathrm{O}_{3}$} & \multicolumn{3}{|c|}{$\mathrm{TiO}_{2}$} \\
\hline & $\begin{array}{l}\varangle \\
\stackrel{\Xi}{0} \\
\frac{\pi}{0}\end{array}$ & $\begin{array}{l}\infty \\
\dot{d} \\
\stackrel{\Xi}{0}\end{array}$ & $\begin{array}{l}0 \\
\text { घี } \\
\text { తే }\end{array}$ & $\begin{array}{l}\varangle \\
\Phi \\
\frac{\Phi}{0}\end{array}$ & 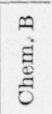 & $\begin{array}{l}0 \\
\text { घू } \\
0 \\
0\end{array}$ & 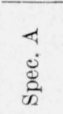 & $\begin{array}{l}n \\
\text { घี } \\
\text { ठ․ }\end{array}$ & 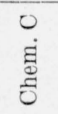 & 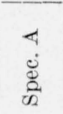 & $\begin{array}{l}\text { n } \\
\text { घี } \\
\text { ฮี }\end{array}$ & $\begin{array}{l}0 \\
\text { घ. } \\
\text { J }\end{array}$ & 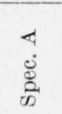 & $\begin{array}{l}\infty \\
\text { a } \\
0 \\
0\end{array}$ & $\begin{array}{l}0 \\
\dot{\Xi} \\
\text { हु }\end{array}$ & $\begin{array}{l}4 \\
\dot{\Phi} \\
\frac{\Phi}{\infty}\end{array}$ & $\begin{array}{l}\infty \\
\text { घี } \\
\text { हू }\end{array}$ & $\begin{array}{c}0 \\
\text { घี } \\
\text { ర్ }\end{array}$ & 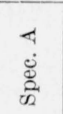 & $\begin{array}{l}\infty \\
\text { घี } \\
\text { ฮี }\end{array}$ & $\begin{array}{l}0 \\
\text { घี } \\
\text { ठ․ }\end{array}$ \\
\hline 1 & 5. 3 & 5.6 & ... & 2. 4 & 2. 4 & ... & 3.6 & 3. 6 & ..... & 0.25 & 0.24 & $\ldots$ & 0.61 & 0.59 & .... & 0.08 & 0.07 & .... & 0. 24 & 0.23 & $\ldots$ \\
\hline 2 & 5.4 & 5.8 & ... & 2. 4 & 2. 4 & ... & 3. 2 & 3. 3 & .... & .37 & .36 & .... & .55 & .45 & $\ldots$ & .11 & $\because 11$ & & .26 & .24 & .... \\
\hline 3 & 4. 6 & 4.7 & 4. 7 & 2. 3 & 2. 1 & 2.3 & 1.4 & 1.0 & 1.1 & .04 & .03 & 0.04 & .20 & .19 & 0.21 & .10 & .09 & 0.08 & .29 & .30 & 0.33 \\
\hline 4 & 4. 5 & 4. 7 & 4. 7 & 2. 9 & 3. 0 & 3.1 & 2.4 & 2.4 & 2. 2 & .05 & .06 & $\begin{array}{l}.07 \\
1.5\end{array}$ & 1.4 & & 1.4 & .14 & .13 & .13 & .23 & .21 & .28 \\
\hline 5 & 5.6 & 5.4 & ... & 2. 6 & 2. 5 & ... & .88 & .71 & .... & .07 & .06 & $\ldots$ & .20 & .19 & .... & .06 & .07 & -... & .26 & .27 & -... \\
\hline 6 & 4. 9 & 4.7 & ... & 3.4 & 3. 5 & ... & 1.9 & 1.9 & .... & .30 & .28 & .... & .50 & .49 & .... & .13 & .13 & ..... & .26 & .26 & .... \\
\hline 7 & 5.4 & 5.4 & ... & 3. 0 & 3.1 & ... & 1. 07 & .94 & .... & .08 & .07 & .... & .44 & .44 & ..... & .17 & .16 & -.... & .30 & .30 & .... \\
\hline 8 & 5.8 & 6.1 & ... & 2. 2 & 2. 3 & ... & 2.1 & 2.1 & .... & .14 & .16 & -... & .02 & .13 & .... & .50 & .50 & -... & .23 & .24 & .... \\
\hline 9 & 4.0 & 4.0 & ... & 3. 2 & 3. 2 & $\ldots$ & 1.2 & 1. 2 & .... & .31 & .25 & -.... & .59 & .44 & .... & .08 & .09 & ..... & .24 & .23 & -.... \\
\hline 10 & 4.8 & 5.5 & ... & 3.8 & 3. 9 & ... & 3.3 & 3.1 & .... & .28 & .26 & .... & .40 & .39 & .... & .06 & .07 & .... & .31 & .30 & ..... \\
\hline 11 & 4. 7 & 4. 3 & 4. 2 & 6. 0 & 5. 4 & 5.5 & .95 & .85 & .71 & .71 & .66 & .70 & .31 & .15 & .15 & .07 & .07 & .06 & .30 & .29 & .36 \\
\hline 12 & 4. 7 & 4.8 & 4. 9 & 4. 8 & 4. 9 & 4.9 & 2.9 & 2.8 & 2.5 & .05 & .05 & .05 & 1.3 & 1.4 & 1.4 & .32 & .30 & .29 & .23 & .21 & .26 \\
\hline 13 & 4. 7 & 4.6 & ... & 5.0 & 4. 9 & ... & 2. 2 & 2. 2 & -.... & .26 & .25 & .... & .55 & .54 & .... & .05 & .06 & .... & .27 & .27 & -... \\
\hline 14 & 5.5 & 5.0 & ... & 2. 3 & 2. 1 & $\ldots$ & 3.8 & 3. 2 & ... & .28 & .28 & .... & .25 & .26 & .... & .09 & .09 & .... & .21 & .22 & .... \\
\hline 15 & 5.4 & 5.2 & ... & 2. 7 & 2. 5 & ... & 1.5 & 1.4 & .... & .29 & .27 & $\ldots$ & .56 & .46 & -... & .07 & .06 & .... & .27 & .27 & ... \\
\hline 16 & 4.5 & 3.9 & 4. 0 & 3.3 & 3. 3 & 3.4 & 2. 7 & 2.3 & 2. 3 & .36 & .32 & .28 & .27 & .26 & .28 & .22 & .22 & $\ldots$ & .22 & .23 & .... \\
\hline 17 & 4. 2 & 4. 6 & 4. 5 & 4.8 & 5. 0 & 5.0 & 2. 6 & 2.7 & 2.4 & .04 & .05 & .05 & 1.1 & 1. 3 & 1.3 & .29 & .32 & .28 & .21 & .23 & .25 \\
\hline 18 & 2.8 & 2.8 & 2.9 & 2. 6 & 2.7 & 2.8 & 1. 6 & 1.7 & 1.8 & .16 & .16 & .15 & .17 & .24 & .28 & .15 & .17 & $\ldots$ & .14 & .16 & ..... \\
\hline 19 & 3.6 & 3.7 & 3.5 & 3. 1 & 3. 1 & 3.2 & 1.2 & 1.0 & 1.4 & .38 & .38 & .33 & .04 & .04 & .01 & .11 & .11 & .... & .17 & 19 & -... \\
\hline 20 & 5. 1 & 4.9 & 4. 7 & 4. 7 & 4. 5 & 4.8 & 1.4 & 1.5 & 1. 6 & 1.09 & 1. 17 & 1. 04 & .16 & .12 & .08 & .10 & .11 & $\ldots$ & .24 & .25 & ... \\
\hline 21 & 3.3 & 3.1 & 3.1 & 3.3 & 3.3 & 3.4 & 1.7 & 1.6 & 1.5 & .08 & .08 & .08 & .35 & .27 & .27 & .09 & .09 & .09 & .16 & .19 & .17 \\
\hline
\end{tabular}

a Chemical values under B and $\mathrm{C}$ are corrected for minor oxides. 
TABLE 6.-Effect of variable operating conditions on apparent composition

[Values in italics represent deviation from standard procedure]

\begin{tabular}{|c|c|c|c|c|c|c|c|c|}
\hline \multicolumn{4}{|c|}{ Operating conditions } & \multicolumn{4}{|c|}{ Apparent composition (weight percent) } & \multirow[b]{2}{*}{ Remarks } \\
\hline $\begin{array}{c}\text { Exposure } \\
\text { time }\end{array}$ & $\begin{array}{l}\text { Output } \\
\text { potential }\end{array}$ & $\begin{array}{l}\text { Vertical dis- } \\
\text { tance between } \\
\text { lower electrode } \\
\text { and optic axis } \\
\text { of spectrograph }\end{array}$ & $\begin{array}{l}\text { Pellett- } \\
\text { forming } \\
\text { load }\end{array}$ & $\mathrm{K}_{2} \mathrm{O}$ & $\mathrm{Fe}_{2} \mathrm{O}_{3}$ & $\mathrm{MgO}$ & $\mathrm{Na}_{2} \mathrm{O}$ & \\
\hline Seconds & $v$ & $m m$ & $l b$. & & & & & \\
\hline 45 & 940 & 3 & 8,500 & 0.28 & 3.6 & 2.8 & 0.42 & Beginning, normal. \\
\hline 40 & 940 & 3 & 8,500 & .21 & 3.5 & 2. 7 & .43 & Exposure time short. \\
\hline 50 & 940 & 3 & 8,500 & .27 & 3.6 & 2.9 & .42 & Exposure time long. \\
\hline 45 & 920 & 3 & 8,500 & .21 & 3.5 & 2. 7 & .43 & Voltage low. \\
\hline 45 & 960 & 3 & 8,500 & .28 & 3.5 & 2.8 & .42 & Voltage high. \\
\hline 45 & 940 & 1 & 8,500 & .28 & 3.5 & 2.9 & .44 & Are position high. \\
\hline 45 & 940 & 5 & 8,500 & .19 & 3.4 & 2.8 & .42 & Are position low. \\
\hline 45 & 940 & 3 & 7,500 & .26 & 3.5 & 2.6 & .41 & Pellett-forming pressure low. \\
\hline 45 & 940 & 3 & 8,500 & .24 & 3.4 & 2.8 & .43 & End, normal. \\
\hline
\end{tabular}

heated to a high temperature to produce a product comparable to cement. This operation may cause alterations in composition, so that checking by means of chemical analysis would still be required.

Table 5 gives a comparison of the spectrographic results (columns A) with chemical results (columns $\mathrm{B}$ and $\mathrm{C}$ ). The spectrographic results shown are the averages of three determinations, and the chemical results are averages of three or more determinations. The chemical results represent work by three well-qualified laboratories, and are in much better agreement than the work of the usual control laboratory. Values in columns B are the results of one laboratory, and those in columns $\mathrm{C}$ are the results of two other laboratories (six samples by one, and four by another).

A summary of these results, in terms of the average differences between the spectrographic (A) and the chemical results of column B, is shown in the third column of table 4 . The average difference between the chemical and spectrographic values for $\mathrm{Al}_{2} \mathrm{O}_{3}$ is given as 0.25 percent, whereas that for $\mathrm{TiO}_{2}$ is 0.01 percent. Because of the differences in concentration between $\mathrm{Al}_{2} \mathrm{O}_{3}$ and $\mathrm{TiO}_{2}$, the above values represent about the same relative accuracy, that is, 5 percent of the concentration. The average difference between the chemical and the spectrographic values for $\mathrm{Fe}_{2} \mathrm{O}_{3}$ and $\mathrm{MgO}$ are a little above 0.1 percent, and for the remaining oxides, except $\mathrm{Al}_{2} \mathrm{O}_{3}$ mentioned above, are well below 0.1 percent.

\section{Precisions required in details of the procedure}

In order to determine the care required in executing certain details of the procedure and to indicate possible sources of error, several series of tests were made: (1) exposure time varied 5 seconds, (2) output potential varied $20 \mathrm{v}$, (3) vertical adjustment of the arc varied $2 \mathrm{~mm}$, and (4) pelletforming load varied 1,000 pounds. The effects of these variations on the observed concentrations of $\mathrm{K}_{2} \mathrm{O}, \mathrm{Fe}_{2} \mathrm{O}_{3}, \mathrm{MgO}$, and $\mathrm{Na}_{2} \mathrm{O}$ are given in table 6 , each result being the average of six determinations. The first and last lines give values for the normal operating conditions. The effects of variations in operational details are considered very small in view of the magnitudes of the variations, which are much greater than will be encountered in routine work with reasonable care.

Nearly as great as the effect of the variations in operating conditions considered above is a warmup effect of the power unit. This may be minimized by running several blanks before starting a series of determinations and also every time the series has been interrupted for a much longer time than that required between exposures.

\section{Advantages and Limitations of the Method}

The chief advantage of the spectrographic method is the short time required to make the analysis. An operator can make duplicate determinations of the seven indicated minor elements in eight portland cements in a day's work and include a visual estimate of other possible minor elements under conditions not adjusted for high speed. Easy extension of the method to include additional elements is a unique characteristic. The direct use of the cement powder is a distinct advantage over methods requiring solution of the sample and chemical separations. Freedom from 
rigorous attention to details makes personal errors much less likely than in chemical methods or even in the earlier direct-current spectrographic method [1].

A limitation of the spectrographic method is the requirement of standard samples. The compounds containing the elements sought and the nature of the major components (bulk of the sample) must be similar for knowns and unknowns, unless tests are made to prove allowable exceptions. The initial cost of spectrographic apparatus is high. This is particularly true for the present method because of the type of excitation required. In view of the speed and laborsaving features, however, the cost per sample analyzed can be very low when large numbers of determinations are required. The type of excitation employed is similar to an interrupted directcurrent arc. The possibility of substituting a simpler means of producing such excitation is suggested.

\section{References}

[1] A. W. Helz, Spectrographic determination of sodium, potassium and lithium in portland cement with direct-current carbon arc, J. Research NBS 34, 129 (1945) RP1633.

[2] B. F. Scribner and C. H. Corliss, An improved electrode holder for spectrographic analysis, J. Research NBS 30, 41 (1943) RP1515.

[3] G. Hansen, Mattscheiben, Z. tech. Physik. 24, 104 (1943)

[4] W. C. Pierce and N. H. Nachtrieb, Photometry in spectrochemical analysis, Ind. Eng. Chem., Anal. Ed. 13, 774 (1941).

[5] W. R. Brode, Chemical spectroscopy, 2d ed. (John Wiley \& Sons, Inc., New York, N. Y., 1943).

[6] M. F. Hasler and H. W. Dietert, A new spectographic source unit, J. Opt. Soc. Am. 33, 218 (1943).

[7] M. F. Hasler and J. W. Kemp, Spectrochemical analysis of metals with the multisource unit, J. Opt. Soc. Am. 34, 21 (1944).

Washington, May 8, 1946. 